\title{
The "Problem" of Male Friendship in Supernatural and Its Fan Fiction
}

\section{Abstract}

This article considers the inclusion of the real-life "slash" fandom in the canon storyline of the CW/WB show Supernatural, and the consequent exploration of the taboo idea raised by the fans: of a sexual relationship between its two central characters, who are brothers. By including references to fan fiction, Supernatural opens a space to question normative sexual identity constructs. This article draws on an argument by Michel Foucault that homosexuality is a social construct that emerged as a way to deal with the "problem of male friendship." In the context of Foucault's argument, Supernatural's treatment of its "slash" fan fiction allows for polysemic interpretations of the brothers' relationship to coexist with the platonic "canon" storyline, opening the door to ideas of sexual fluidity and the "queering" of its characters by fans.

Keywords: fan fiction, sexual identity, Foucault, intimatopias, Supernatural

\section{Introduction}

Supernatural is an American primetime show centered on a monster-of-the-week mystery format, led by the fictional brothers Sam and Dean Winchester (played by Jared Padalecki and Jensen Ackles), hunters of supernatural phenomena. In the fourth season, the brothers are in the midst of their usual investigation when they discover a book series that tells their own life story. As they begin to investigate this odd phenomenon, they discover that this book series has fans. Thus, the show's real-life fandom is integrated into the "canon" storyline. What follows is an immediate reference to "slash" ("The Monster"). 
Slash is a type of erotic fan fiction named for the "l" separating two male character names. The slash mark indicates a sexual pairing between two characters whose relationship is platonic in the "canon," although emotionally intimate. Slash remains the most controversial genre of fan fiction, and also the most popular within Supernatural fandom (Felschow par. 6.1; Larsen and Zubernis 33). In the case of Supernatural, the writing of slash is complicated since it takes the friendship at the emotional core of the show and makes it incestuous. Therefore, when Sam and Dean discover "their" slash, their reaction is disgust:

Dean: There are "Sam" girls and "Dean" girls and... what's a slash fan?

Sam: (With a repulsed expression) As in... Sam-slash-Dean. Together.

Dean: Like... together, together?

Sam: Yeah.

Dean: They do know we're brothers, right?

Sam: Doesn't seem to matter.

Dean: Oh, come on. That... That's just sick. ("The Monster”)

This storyline, in which Supernatural makes direct references over several seasons to slash fan fiction, provides a unique ${ }^{[1]}$ opportunity to explore actual moments of interplay between seemingly contradictory readings of the brothers' relationship.

There are many arguments as to why people write erotic fan fiction (Booth 397; Cicioni 175; Green et al. 17; Katyal 496; Kustritz 373; Tosenberger par. 1.1), but the most interesting argument to explore in the context of a show that acknowledges its own fan fiction is that slash writers are in fact developing a subtextual reading of the source material. Moreover, the interplay between the show's "official" characterization of the brothers' relationship in the show and the fan characterizations allows for a nuanced, reflexive, complex reading of homosocial/homosexual male relationships and of queer/straight identity constructs in dominant and subversive discourses. Through their acknowledgement of slash, Supernatural neither fully rejects the slash readings, nor does it sanction them. The show's reaction exists in a space between those two extremes, in a gray area where a multiplicity of meanings coexists, and where what it means to queer characters 
is less about a gay/straight dichotomy and more about an increasing acknowledgement of the fluidity of sexuality.

This article draws on fan writing that interprets the male relationships in the show in ways that deconstruct the notion of sexual identity as stable or binary. Supernatural itself absolutely does not reject normative sexual identity constructs; in fact, it generally reproduces normative and essentialist depictions of gender and compulsory heterosexuality. Thus, its tacit acknowledgement of slash, which opens a space for multiple interpretations to coexist, demonstrates unexpected moments of resistance to dominant discourses surrounding sexuality. Through its humorous inclusions of slash, Supernatural has pointed its audience toward readings of its characters that exist within the realm of the taboo, the "abnormal," and probably the distasteful, for many. While these affirmations of slash may not have been intended to act as form of resistance to normative discourse - indeed, the creators' motivation may have been entirely commercial - the show has in fact disrupted the normative binary of sexual identity in no small way. The show has fostered a space for questioning sexual identity through the incorporation of slash, resisting the need to assign a fixed interpretation of the brothers' relationship.

The first section of this paper draws on an interview with Foucault, in which he argues that the concept of binary sexual identity was historically constructed, in connection with what he refers to as the social disappearance of male friendship. Following this point, this article argues that the slashing of the Winchester brothers has met with resistance in part because the disappearance of emotional male friendship has such deeply felt cultural reverberations. The need for strong fictional depictions of emotional male friendship is, however, in tension with the need for representations of diverse sexuality. Secondly, this article offers a few examples from the Supernatural slash that demonstrate a concept borrowed from Elizabeth Woledge called "intimatopias" (106) or a creative vision of a world beyond sexual identity![2] This section considers how fan writing is an interplay with dominant discourses, rewriting the scripts for Supernatural without rewriting the characters' sexual identities. Finally, this paper analyzes a few relevant scenes from the show, in which we see the direct engagements with slash. From these scenes, we see how the show has created a space for the alternate sexual characterizations suggested by slash. 


\section{Reading Homosexuality after the Eighteenth Century}

Jensen Ackles, the actor who plays Dean Winchester, made the following comment regarding slash interpretations of the brothers' relationship, quoted by Larsen and Zubernis:

"We play brothers on screen, but we're kinda [sic] brothers off screen as well. It's a brotherly love that he and I have and it's kind of disappointing to me that people would mistake that for a sexual kind of love." So for Jensen, it wasn't a matter of being disturbed by the content of fan practices but by a culture that has trouble accepting friendship between men for the lovely thing it is all by itself.

This sense of disappointment that male friendship is misunderstood through eroticization is interesting to consider in the context of the following argument made by Foucault. He wrote that the emergence of homosexuality as a construct happened only in the 18th century and became a "problem" for society only through the disappearance of male friendship over the course of the 16th and 17th centuries ("Sex, Power" 170-71) ${ }^{[3]}$ Foucault's hypothesis was that male friendship gradually lost its importance as a culturally accepted institution, in part due to active suppression, and that it was only once this happened that homosexual acts became socially transgressive. Before that point, he argued, it did not matter if men were engaging in homosexual activity; it had no social significance: "the disappearance of friendship as a social relation and the declaration of homosexuality as a social/political/medical problem are the same process" ("Sex, Power" 171). At its surface, Ackles's disappointment at the fans of Supernatural "mistaking" the Winchesters' love for sexual love seems a clear example of this. If we live in a culture that is lacking in literary or filmic depictions of deep and emotional male friendships, as noted by Garlick (560), one can understand why turning one such platonic friendship into a sexual relationship could feel like a betrayal to its creators. One could even argue that the incest taboo is so prevalent in Supernatural slash because male friendship, as a cultural institution, has become so difficult to accept that it is almost impossible for viewers to interpret any such intense, affective relationship between men platonically - even when the friends in question are brothers. The incest taboo, therefore, becomes actually easier to overcome than the "problem" of male friendship. 
Foucault's argument is that male friendships began to be something "other" than friendships and disappeared from "male society" over the course of the 16th and 17th centuries: "[y]ou can find, from the sixteenth century on, texts that explicitly criticize friendship as something dangerous" ("Sex, Power" 170). He argues that dominant discourses suppress male friendship because the institutions of modern society "cannot function with such intense friendships" ("Sex, Power" 170). According to Foucault, these friendships posed a threat because they were social relationships in which people had "a certain freedom, a certain kind of choice" ("Sex, Power" 170). Therefore, friendships were reinterpreted as something else, which led to the concept of homosexuality:

As long as friendship was something important, was socially accepted, nobody realized men had sex together. You couldn't say that men didn't have sex together - it just didn't matter. ... Once friendship disappeared as a culturally accepted relation, the issue arose: "What is going on between men?” (“Sex, Power” 171)

Foucault argued that dominant texts began to refuse to acknowledge male friendship. This idea has been developed by other scholars, such as Eve Sedgwick, who described this disappearance of male friendship as a form of strict homophobia imposed on men:

To draw the "homosocial" back into the orbit of "desire," of the potentially erotic, then, is to hypothesize the potential unbrokenness of a continuum between homosocial and homosexual - a continuum whose visibility, for man, in our society, is radically disrupted. (696)

On its surface, Supernatural, a mainstream television show that is otherwise fairly reliant on hegemonic depictions of gender norms, masculine ideals, and compulsory heterosexuality, but is also centered on loving and emotional male friendships, seems to contradict - or at least to complicate - Foucault's argument. Yet, when slash authors reinterpret the relationship as sexual, does not that rather substantiate it, by suggesting that male friendship is so problematic that it must be reinterpreted as something sexual?

If so, this would undermine much of fan fiction scholarship that sees the "canon" as a representation of dominant discourse,$^{[4]}$ and slash, or fan fiction more generally, as a representation of subversive or transgressive ideas. For example, Booth writes that slash is 
subversive because it "renegotiates the boundaries of gender norms, character relationships and heteronormativity in popular media" (399-400). However, this type of rather reductive generalization has repeatedly been challenged. For example, Scodari writes that "the very act of fans creatively laboring to adjust commercial texts to their interests is remarkable, but their particular adjustments or the motives behind them are not always resistive" (113). By this logic, the canon could in fact be engaging in a subversive representation of male friendship, whilst slash writers reinforce a more dominant discourse that male friendship cannot possibly exist, and therefore must be something "other." If so, what then can be made of the incorporation of slash by the canon? Consider the following, in which Graham argues that the integration of fan texts within Supernatural makes their discourses part of the canon:

Rather than seeing fans as hacks who borrow from texts without permission, the episodes discussed here seem to indicate that the writers and producers of the series see fans as a creative force of their own, one to be listened to at the least and offered respect at the most. For fans, acknowledgment of their work "within the series' narrative" means "their discourses are now canonical." (143-44)

By integrating the fan discourse of a sexual relationship between the characters, does Supernatural substantiate it? If so, this might demonstrate Foucault's point clearly, by showing that male friendship is so unacceptable in dominant discourse that suggestions of incest are in fact sometimes preferable. However, the way slash has been integrated does not read as a direct substantiation, but merely an interplay. It is worth considering that if the show's writers were overtly trying to emphasize the importance of platonic male friendship, it would make very little sense to reference slash. The much likelier reading is that neither the slash nor the television show is necessarily wholly subversive, nor is either necessarily completely committed to the (re)production of normative discourses. Rather, in both, there are elements of perpetuating gendered and sexual binaries and norms, and of resisting them.

Furthermore, there is a significant impasse in attempting to argue through a Foucauldian lens that depicting platonic male friendship is subversive - because his language is quite clear that the male friendships to which he was referring did not need to be asexual. Foucault is not building a 
dichotomy of friendship versus sexual relationships. In fact, what he is urging is a discursive separation between sexual activity and sexual identity. He addresses this directly:

If we are asked to relate to the question of identity, it must be an identity to our unique selves. But the relationships we have to have with ourselves are not ones of identity, rather, they must be relationships of differentiation, of creation, of innovation. ... We must not exclude identity if people find their pleasure through this identity, but we must not think of this identity as an ethical universal rule. ("Sex, Power" 166)

For Foucault, forming a defined sexual identity is a limiting prospect. If we do so, we may prevent ourselves from engaging in pleasurable activity if it falls outside the bounds of our preconceptions of identity. Therefore, when he argues that prior to the 18th century there was no homosexuality, only what men did, he means that sexual identity, in itself, is a construct, and one from which we may attempt to step away. In this respect, it is the concept of sexual identity that is most normative. Therefore, as this article will later demonstrate, by nudging toward slash, and thereby slightly loosening the holds on its characters' fixed identities, Supernatural has made a small act with transgressive potential. This is less surprising than one might think since it does not necessitate a reading of Supernatural as an entirely resistant enterprise, as Foucault argues:

Where there is power, there is resistance, and yet, or rather consequently, this resistance is never in a position of exteriority in relation to power. ... These points of resistance are present everywhere in the power network. ... There is a plurality of resistances, each of them a special case: resistances that are possible, necessary, improbable... (The History 95-96)

Indeed, there is a level of improbability to the notion that a network television series should resist powerful discourses regarding sexual identity, and it may or may not have been done purposefully. Certainly, there is a strong potential economic motive to incorporating slash ("pandering" to fans); moreover, the inclusion may have been meant to undermine slash, as Felschow argues (par. 6.6). However, through integration of the fan writing, a form of resistance to dominant discourses regarding sexual identity has been achieved, if only because so much of the slash writing in itself provides an alternative mode through which to view sexual identity. 
Indeed, if we think of sexual identity as a restraining construct, the slash writers are not "mistaking" brotherly love for sexual love but refusing to be limited by a constructed binary between platonic and sexual love. For many slash writers, it would seem that viewing the brothers' relationship as either sexual or friendship is overly simplistic. The characters' fulfillment of their intimate bond in sexual activity within slash does not negate their friendship within the show because, as Green et al. argue, the characters are distanced from reality due to their placement in the alternate universes of fantasy (22). Furthermore, they quote Tosenberger, who theorizes that "[i]n Supernatural slash, fannish representations of incest posit Sam and Dean's romantic attachment as merely 'an extension and intensification' of their already overwhelming love" (par. 4.8). As will be demonstrated, the fact that this subtext has been repeatedly pointed to by the show suggests that, even within the canon, there is space for polysemic readings of the relationship, and therefore the binary of friendship/sexuality is a false one.

\section{Worlds That Complicate Sexual Identity}

Woledge introduces the term "intimatopias" to describe fan fiction worlds in which "the social closeness of the male characters engenders intimacy" ("Intimatopia" 100). Woledge asserts that, rather than the male characters within intimatopic slash fiction needing to "come out" or otherwise change their narratives of sexual identity from those present in the source material, "the homosocial community supports homosexual activity by the creation of societies in which it is only 'logical' for social intimacy to engender sexual ties" (“Intimatopia” 101-02). For instance, in one slash story, Dean tells a friend that his sexual relationship with Sam "is about the only normal that makes sense for us" (morganaDW). The friend greets the discovery of the incestuous relationship between the brothers with understanding, rather than revulsion, because within the intimatopia the sexual relationship between the brothers is the logical extension of their intimacy. Thus, sexual acts need not have any effect within the intimatopia on the characters' sexual identities. The characters within fan depictions often remain what they are in the show, not only heterosexual but forcefully performing masculinity. Indeed, it is not a question of their sexual identities being altered or infringed upon in any way from those in the television show: "[m]ost of the texts ... make no direct reference to modern day homosexual identities, and indeed some ... quite explicitly distance 
themselves from them. Nonetheless, many of them depict sexual or at least ambiguously eroticized relationships between men" (Woledge, "From Slash" 51-52).

Not all Supernatural slash stories could be termed intimatopias. Some do involve rewritten origin stories for the characters, sometimes involving "coming out" narratives, and there are stories where the characters are so thoroughly rewritten that they appear to share very few, if any, characteristics with their canonical counterparts. However, fan fiction also frequently appears in which the characters closely resemble those in the television show, and even the plots closely mirror those presented in the television series. In these stories, the point of departure from the original is normally that the plot develops into erotica, usually maintaining the characterizations from the show (in other words, developing the subtext). As Woledge argues, these plots depict sexual or eroticized relationships between men, building on the relationships from the show. Take, for example, this story in which Dean is paired with the male angel Castiel[ ${ }^{[5]}$ "One of the angel's hands is cupping Dean's cheek and the other is on his right bicep, right over the mark he made pulling Dean out of hell" (waldorph). This passage uses details pulled from the television show such as "the mark he made pulling Dean out of hell," to situate itself within the world a Supernatural fan is familiar with. The details about Dean in the story establish him as the same heterosexual character he is in the show. Yet, without any explanatory device, he is depicted in an intimate situation with Castiel.

In other stories, there is some reproduction of dominant discourse. For instance, writers show that the sexual activity between supposedly straight men might be considered inappropriate by other characters - for example, in this passage, in which Dean speaks:

"We were never normal, Cas. We hunt the supernatural. There's nothing normal about that." ... He waited for a moment before glaring at Castiel and saying, "if you ever tell Sammy this, I will hurt you." Castiel smiled, and nodded, leaning forward and gently kissing Dean. (2ofacrime24)

Here, there are several references that situate the reader within the television series - including the hunting of the supernatural and a hyper-aggressive characterization of Dean, which ties into his character's aggressive performance of masculinity. There is also an implication that the sexual relationship between the characters would not be well received by his brother; while the reason is 
not explicit, it implies that homosexual activity would be considered objectionable. On the other hand, there is no indication anywhere in the story that the character's sexual identity is changed because of the activity - he is not depicted as gay, but simply as in love with Castiel, a reading which is clearly a development of a close relationship within the canon.

The continual engagement in gay sex by straight-identified characters in slash has prompted discussions related to homophobia (Cicioni 175; Green et al. 22). Woledge addresses these criticisms; she claims there are several reasons why writers of intimatopias may distance themselves from gay narratives or identities, and some of these reasons are well worth examining in the context of Foucault's ideas around sexual identity:

Many writers of intimatopic slash fiction share ... the desire to "liberate sexual love from homosexual love" ... Under this rubric, many writers do not want to confine their fictions to existing stereotypes by labeling their stories or their characters as homosexual and thus sacrificing a universal view for the particular, and risking their texts' losing their polysemy and becoming "univocal," ... Intimatopia is a world separate from our current realities ... a world of male intimacy, yes, but not the world of the modern homosexual. ... It is not homophobic so much as homoindifferent. (Woledge, "Intimatopia" 102-03)

The word "homoindifferent" is a stretch considering the plethora of male-on-male sex being described in slash, as well as the frequency with which slash stories do include gay narratives and identities. However, Woledge's point is that intimatopias are simply not about sexual identity. Indeed, the many stories in which canonically straight-identified characters are engaging in male/male erotic activities without any references to questions of sexual identity reflect her argument that these fictional worlds operate under their own discourses. These worlds in which sexual identity and activity are separate are so numerous within Supernatural slash that within this context they are entirely normative.

Of course, the discourses operating within these intimatopias are not separate from real-world discourses. Both fictional and real examples of fluid sexual identity can be found in other areas than slash, just as labeling and categorization of sexual identities, as well as homophobia, misogyny, and other operations of power, do make their way into slash. These varied types of discourses coexist in slash just as they do outside of fan fiction, since their authors are operating 
within real world contexts. There is not a complete separation of discourse in different spaces; however, within Supernatural slash, the separation of sexual activity from identity is not unusual. Indeed, there is one final area of slash that reinforces this reasoning; there are multiple websites devoted to the slashing of Jared Padalecki and Jensen Ackles, the principal actors, and this has its own monikers: "J2" or "J Squared." The "J2" slash has a largely different tone. Since it takes place in a fictional version of the real world, as opposed to a reimagined version of the Supernatural world, it tends to copy discourses present in real-world environments, and therefore coming-out narratives are much more common in "J2" slash (Flegel and Roth par. 1.2). By contrast, the lack of importance placed on sexual identity in the Sam/Dean slash (or, as fans refer to it, "Wincest") and Dean/Castiel ("Destiel”) slash is that much more apparent.

\section{Supernatural Engages the Fan Fiction}

As mentioned in the introduction, in Supernatural's fourth season, Dean asks Sam, "[d]on't they [the fans] know we're brothers?" to which Sam replies, "[i]t doesn't seem to matter" ("The Monster"). In fact, a closer look at the Supernatural slash shows that this assumption is incorrect; to most slash writers, it does matter. In fact, the incest is frequently the highlighted part of the fantasy. For example, "It may have taken them years to get to this moment but Sam finally has his brother in his bed and he's not letting him go" (Cozy_coffee). Many taboos are routinely explored by slash. However, there are also many stories in which the characters are romantically paired, but incest references are avoided. For example, in one episode of Supernatural, Sam and Dean are thrown into an alternate universe where they are not brothers, and slash stories frequently take place within that universe (e.g., jenajasper).

It is quite possibly due to the incest that the show writers were able to mention slash at all, because this component allowed them to immediately dismiss the fan readings of the relationship between Sam and Dean as "sick." As Graham argues, "incestuous fiction, whether heterosexual or homosexual in nature, still moves in taboo territory" (138-39). As she speculates, were this Star Trek making reference to Kirk/Spock slash, or Buffy the Vampire Slayer making reference to Angel/Spike, a character could not as easily say, "That's just sick," because they would prompt charges of homophobia (Graham 138-39). However, because incest remains so much more 
unthinkable in dominant discourse, Dean can freely show his disgust. To be sure, the taboo also makes the very inclusion of slash in the show that much more surprising - particularly because many references to "Wincest" follow.

For instance, in the opening episode of the fifth season, we are introduced to the minor character of Becky, a "fangirl." Becky sits at her computer, reading melodramatically, as she writes: "And then Sam touched - no - caressed Dean's clavicle. 'This is wrong,' said Dean. 'Then I don't want to be right,' replied Sam, in a husky voice" ("Sympathy for the Devil”). This joke does not depend on prior knowledge of slash; Becky is writing about sex between the brothers. However, the joke has a deeper level for those familiar with slash: slash often uses this type of moral language and describes Sam and Dean overcoming their sense that their love is forbidden. For example,

Most people would've reacted badly to the scene you walked in on earlier, especially if they knew we were brothers. One day, I'll give you the condensed version of our screwed up lives but... what we have, while morally wrong and illegal, is about the only normal that makes sense for us. (morganaDW)

Becky is an inside joke for slash writers, but she is also a mockery of them. Becky's writing is interrupted by a call from Chuck Shurley, the fictional author of the Supernatural book series. He asks her to get a message to Sam and Dean and she is initially offended: "Yes, I'm a fan, but I really don't appreciate being mocked. I know that Supernatural is just a book, okay? I know the difference between fantasy and reality" ("Sympathy for the Devil”). Chuck informs her that "it's all real," and Becky replies: "I knew it!" As a stand-in for slash writers, Becky is a somewhat insulting figure. As Graham argues, "Becky is the clichéd fangirl taken to its most ridiculous ends. While she claims to be able to separate fantasy from reality, she cannot" (141). However, this is a surface level reading of Becky. Although the writers are certainly playing her for laughs, it is doubtful that their intent would be unmitigated ridicule of the fans, since a cult show relies on its following (Felschow par. 6.7). For one, within the context of the show, Becky is right - it is real - and she only exists within that context. Moreover, Supernatural slash has a more complicated relationship with the fiction vs. reality dichotomy than many other fandoms. 
Flegel and Roth point out that while "Real Person Slash" (RPS) is "often constructed as the genre even slashers look down upon," (22) Supernatural invites more than the usual amount. This could be explained as a discomfort with incest (by writing about the actors, who are not brothers, slash writers can avoid incest), but this does not explain the large number of writers who write both "Wincest" and "J2" slash, nor does it explain stories that contain both (Flegel \& Roth 22; sandymg).

The introduction of Becky is a great comedic moment in the show precisely because there are many layers to the joke. She introduces herself to Chuck as the "webmistress of morethanbrothers.net" ("Sympathy for the Devil") - again, the show is taking care to remind us about "Wincest." In many depictions of fans within popular media, the writing of fan fiction itself is considered odd enough to be a standing joke, as Kustritz contends, citing examples such as the film Misery ${ }^{[6]}$ and the documentary Trekkies:

Being a fan is clearly not the type of life one is supposed to lead. Both the news media and the entertainment industry would have us think that we know exactly what fans are like. ... [they imply that] fandom is an activity shared by the very young or by underdeveloped adults who are sorely lacking in the social skills that would allow them to lead a "normal" life. (375)

Clearly, there is no need to reference slash to make Becky seem comical; even within Supernatural, there are many fan-centered jokes that have nothing to do with slash. And yet, the show's writers have not confined themselves to these areas; instead, we have a mainstream television show repeatedly reminding us that its fan fiction sexualizes the brothers. In season ten, there is an episode called "Fan Fiction," in which the brothers investigate a disappearance at a high school only to discover that the teenage students are in the midst of mounting Supernatural, a musical based on the book series. In this episode, not only are there repeated references to "Wincest," but the show frequently uses self-deprecating humor that opens out the "canon" to include fan depictions and critiques. For example, consider the following conversation between Dean (who is masquerading as an FBI agent) and the Supernatural musical's student director, Marie, in which she points to the show's rather clichéd writing: 
Dean: (Referring to the girls playing "Sam" and "Dean") What are they doing? Marie: Oh! Um, they're rehearsing the B.M. scene.

Dean: The bowel movement scene?

Marie: No! The boy melodrama scene. You know, the scene where the boys get together, and they're - they're driving, or leaning against Baby [their car], drinking a beer, sharing their feelings the two of them, alone, but together. Bonded. United. The power of the brotherly -

Dean: Why are they standing so close?

Marie: Um... reasons.

Dean: You know they're brothers, right?

Marie: Well, duh. But... subtext.

Dean: Why don't you take some steps back there, ladies? ("Fan Fiction")

This is a joke not just for the slash writers and readers, but for any fan who would be all too aware of the "boy melodrama" scene. For many slash writers, this ubiquitous scene forms the basis of their readings. Are Sam and Dean's "boy melodrama" scenes a part of a natural relationship between adult brothers, or do they indicate potentially sexual feelings? According to Paul Booth, "[o]ne interpretation of slash sees its transgressive potential as the most relevant factor in its writing; another interpretation acknowledges slash's normative and ideological similarities to the text it references. These are not clear-cut categories, and slash is inherently multifaceted" (400). Even a quick perusal of Supernatural slash demonstrates this latter point, and no argument could apply to the genre as a whole. However, many of the stories feature this exact trope from the show, with sexual scenes developing from the moments when the brothers are in the car or leaning against it, talking about their feelings (i.e., BabyBat; hemmingskfc). Larsen and Zubernis argue that "the show itself provides a wealth of subtext that fans have used" (102), and they further note that "[i]n Supernatural, the emotion-filled intense looks often exchanged between Sam and Dean are the backdrop for Wincest, and similarly intense looks between Castiel and Dean are the basis of the pairing known as Destiel..." (123-24).

By raising the topic of slash in the context of satirizing their own writing in the "Boy Melodrama" scene, the show's writers recognize the different interpretations of the relationships between their 
characters. This is not only because they acknowledge the existence of slash, but also because of the lightheartedness of the scene. The reaction is no longer outright disgust, or portraying the "fangirl" as ridiculous, as in the previous instances in which slash was referenced. No longer is it just Becky the fangirl who is silly; now, the show's own writing is ridiculed. Moreover, Marie's answer to the question, "Why are they standing so close together?" of "Um... reasons," requires an awareness of slash on the part of the viewer. Moreover, Marie's line, "But... subtext," reinforces the notion that slash depictions have developed from the show.

This episode continues to ridicule the show's own writing and play the "Wincest" for laughs. A scene begins with Dean scoffing about fan fiction, and then summing up the actual plot of the last few seasons, which Marie pronounces to be the "worst fan fiction" she has ever heard. Here, the writers of the show are playfully demonstrating their awareness of poor critical and fan reception of the past several seasond ${ }^{7]}$ (e.g., Ryan). By juxtaposing Marie's fan fiction with their own writing in this way, they are blurring the lines around the canon. Although not an outright validation of slash readings, it is at least a recognition of their existence, and an acknowledgement of the possibilities of interpretation, with a bit of a wink ("Fan Fiction"). It is clear that the tone of the fan fiction references has changed over time: the characters at this school, led by Marie, are making much more nuanced arguments about the relationship between the canon and fan fiction - at least in comparison to the first discovery of slash in the fourth season.

This episode contains one last direct reference from Marie to the argument that slash is a subtextual reading of the relationship:

Marie: ... we do explore the nature of Destiel in Act Two.

Dean: Sorry, what?

Marie: Oh, it's just subtext! But, then again, you know, you can't spell subtext without... s-e-x.

The scene then cuts away to Dean, who has presumably just told Sam what he learned from Marie:

Sam: I don't understand.

Dean: Me neither. 
Sam: I mean, shouldn't it be... Deastiel?

Dean: Really? That's your issue with this?

Sam: No, of course it's not my issue. You know... how about... Sastiel? Samstiel?

Dean: Okay, all right. You know what? You're gonna do that thing, where you just shut the hell up, forever. ("Fan Fiction")

Here, the reference to "Destiel," a slash pairing that is not incestuous, is the most positive reaction yet from either brother regarding slash. For the first time, Sam is willing to entertain the notion of slash, albeit facetiously. Furthermore, although we continue to see Dean experiencing discomfort with the idea, Sam's suggestion means that a straight-identified character is cracking jokes about the idea of erotic storylines involving himself and another man. While the scene is certainly not validating the slash readings in which sexuality is a natural and normal expression of the brothers' love, or of the love between Dean and Castiel, it is demonstrating a willingness to loosen the bounds of authority around the canon. That this is done whilst the brothers are talking about sexuality certainly points towards Foucault's notion of the potential for discursive separation between identity and sexual activity.

\section{Conclusion}

This article considered the possibility that incest slash is so prevalent within Supernatural fandom in part because, as Foucault argues, male friendship is now such a culturally problematic institution that the normative reaction to a depiction of an affective, loving, emotional relationship between men is to interpret it as sexual. Ultimately, however, the prevalence of "Wincest" slash does not necessarily demonstrate discomfort with male friendship because so much of it fits more broadly into what Woledge terms "intimatopias," or worlds in which the sexual contact between male friends is a logical extension of their intimacy, rather than a betrayal of their platonic friendship. Following Foucault's argument regarding the disappearance of male friendship and the discursive rise of "homosexuality," the worlds created by slash writers are looking beyond the confines created by sexual identities. As Kingston writes, Foucault's work on challenging homosocial norms in this respect "will clear the space needed for an experimental friendship" (15). This is not meant 
to be a homophobic negation of gay identity, nor a framing of heterosexuality as a neutral identity. Much the opposite: the slash texts mostly suggest an invitation to the reader to make her own inferences about a character's identity, whether sexual or otherwise. They often suggest a desire for the characters and stories to remain mostly the way they are within the confines of the television show, with the exception that their emotional involvement with each other is realized erotically. Finally, they suggest a desire for the characters and relationships to exist in multiple forms, where sexual and platonic do not need to be opposites. Fundamentally, it is this latter reading that offers the greatest possibilities; it offers the potential for seeing moments of resistance to the norms of sexual identity, not only within fan writing but within mainstream discourse. It picks up on "Foucault's work on homosexuality and social experimentation [which] thus describes a novel form of friendship" (Kingston 15).

Whether or not the writers of Supernatural intended their inclusion of slash to make a statement about the fluidity of their characters' sexuality, they have opened a door between their own fictional world and the online slash "intimatopias." This has occurred through repeatedly referencing slash, making cracks about "subtext," and having Sam speculate about possible portmanteaus for Sam/Castiel. Supernatural's inclusion of multiple slash references is a unique and unusual type of acknowledgement of fandom. Regardless of the motives, the integration of fan fiction into the script focuses in particular on eroticized interpretations of its main characters, including the especially popular and controversial "Wincest" slash. The show's use of the word "canon" points to the blurred lines of authority between show writer and fan writer. The writers of the show also repeatedly point to the argument that slash is developed from subtext. Furthermore, they entertain polysemic character interpretations by shifting the tone of Sam's reactions to the existence of slash. Over time, his revulsion turns into amused bewilderment. Sam's altered reaction points to a changing perspective on the part of Supernatural's writers. Through their acknowledgement of slash, while they never quite sanction fans' reinterpretations, they do make space for these readings to coexist within the canon. 


\section{Works Cited}

2ofacrime24. "Right." Supernatural fan fiction. Archive of Our Own, 23 Aug. 2009, http://archiveofourown.org/works/587837. Accessed 15 Sept. 2018.

BabyBat. "12 Days of Wincest." Supernatural fan fiction. Archive of Our Own, 13 Dec. 2015, http://archiveofourown.org/works/5409848/chapters/12517397. Accessed 15 Sept. 2018.

Booth, Paul. "Slash and Porn: Media Subversion, Hyper-Articulation, and Parody." Continuum: Journal of Media \& Cultural Studies, vol. 28, no. 3, 2014, pp. 396-409.

Cicioni, Mirna. "Male Pair-Bonds and Female Desire in Fan Slash Writing." Theorizing Fandom: Fans, Subculture and Identity, edited by Harris, Cheryl, and Alison Alexander, Hampton Press, 1998, pp. 153-77.

Cozy_coffee. "Diamond Boy." Supernatural fan fiction. Archive of Our Own, 24 Nov. 2015, http://archiveofourown.org/works/5280242. Accessed 15 Sept. 2018.

"Fan Fiction." Supernatural, produced by Eric Kripke, season 10, episode 5, The CW, 11 Nov. 2014.

Felschow, Laura E. "'Hey, check it out, there's actually fans': (Dis)Empowerment and (Mis)Representation of Cult Fandom in Supernatural." Transformative Works and Cultures, vol. 4, 2010.

Flegel, Monica, and Jenny Roth. "Annihilating Love and Heterosexuality without Women:

Romance, Generic Difference and Queer Politics in Supernatural Fan Fiction." Transformative Works and Cultures, vol. 4, 2010,

https://journal.transformativeworks.org/index.php/twc/article/view/133/147. Accessed 15 Sept. 2018.

Foucault, Michel. The History of Sexuality, Volume 1. Random House, 1978.

Foucault, Michel. "Sex, Power, and the Politics of Identity." The Essential Works of Foucault, 19541984: Vol. 1. Ethics: Subjectivity and Truth, edited by Paul Rabinow, New York Press, 1982, pp. 163-73. 
Garlick, Steve. "The Beauty of Friendship: Foucault, Masculinity and the Work of Art." Philosophy and Social Criticism, vol. 28, no. 3, pp. 558-77.

Graham, Anissa. M. "A New Kind of Pandering: Supernatural and the World of Fan Fiction." Fan Culture: Essays on Participatory Fandom in the 21st Century, edited by Barton, Kristin M., and Jonathan M. Lampley, McFarland and Co, 2014, pp. 131-45.

Green, Shoshanna, Cynthia Jenkins, and Henry Jenkins. "Normal Female Interest in Men Bonking: Selections from The Terra Nostra Underground and Strange Bedfellows." Theorizing Fandom: Fans, Subculture and Identity, edited by Harris, Cheryl, and Alison Alexander, Hampton Press, 1998, pp. 9-38.

hemmingskfc. "All we do is think about feelings that we hide." Supernatural fan fiction. Archive of Our Own, 7 Sept. 2015, http://archiveofourown.org/works/4750160. Accessed 15 Sept. 2018. jenajasper. "Five o'clock world." Supernatural fan fiction. The Sam/Dean Slash Archive, n.d., http://samdean.archive.nu/viewstory.php?sid=5181. Accessed 15 Sept. 2018.

Katyal, Sonia K. "Performance, Property and the Slashing of Gender in Fan Fiction." Journal of Gender, Social Policy and the Law, vol. 14, no. 3, 2006, pp. 461-518.

Kingston, Mark. "Subversive Friendships: Foucault on Homosexuality and Social Experimentation." Foucault Studies, no. 7, pp. 7-17.

Kustritz, Anne. "Slashing the Romance Narrative." The Journal of American Culture, vol. 26, no. 3, 2003, pp. 371-84.

Larsen, Katherine, and Lynn S. Zubernis. Fangasm: Supernatural Fangirls. lowa Press, 2013. morganaDW. "Thanksgiving Interrupted." Supernatural fan fiction. Archive of Our Own, 27 Nov. 2015, http://archiveofourown.org/works/5295293. Accessed 15 Sept. 2018.

Ryan, Maureen. “'Supernatural' Farewell: Why I gave up weekly Winchester reviews." Huffington Post, 10 Dec. 2011, https://www.huffingtonpost.ca/entry/supernatural-season-7_n_1140853. Accessed 15 Sept. 2018.

sandymg. "Let it out." Supernatural fan fiction. Archive of Our Own, 19 June 2011, http://archiveofourown.org/works/213445?view_adult=true. Accessed 15 Sept. 2018. 
Scodari, Christine. "Resistance Re-Examined: Gender, Fan Practices and Science Fiction Television." Popular Communication, vol. 1, no. 2, 2003, pp. 111-30.

Sedgwick, Eve K. Between Men: English Literature and Male Homosocial Desire. Columbia University Press, 1999.

Spargo, Tamsin. Foucault and Queer Theory, Totem Books, 1999.

"Sympathy for the Devil." Supernatural, produced by Eric Kripke, season 5, episode 1, The CW, 10 Sept. 2009.

"The Monster at the End of this Book." Supernatural, produced by Eric Kripke, season 4, episode 18, The CW, 2 April 2009.

Tosenberger, Catherine. “The epic love story of Sam and Dean': Supernatural, Queer Readings, and the Romance of Incestuous Fan Fiction." Transformative Works and Cultures, vol. 1, 2008, https://journal.transformativeworks.org/index.php/twc/article/view/30/36. Accessed 15 Sept. 2018. waldorph. "My brother's keeper." Supernatural fan fiction. Archive of Our Own, 23 Sept. 2008, http://archiveofourown.org/works/61108. Accessed 15 Sept. 2018.

Woledge, Elizabeth. "From Slash to the Mainstream: Female Writers and Gender Blending Men." Extrapolation, vol. 46, no. 1, 2005, pp. 50-66.

Woledge, Elizabeth. "Intimatopia: Genre Intersections between Slash and the Mainstream." Fan Fiction and Fan Communities in the Age of the Internet, edited by Hellekson, Karen, and Kristina Busse, McFarland and Co., 2006, pp. 97-114. 
[1] See Graham, who defines the inclusion of fan fiction in Supernatural's script as a new kind of "pandering" to the fans (131), or Felschow (par. 4.6), who points out that while "sly" nods to fandom are nothing new, such direct references are a first.

[2] Tosenberger also uses this idea to describe Supernatural slash (par. 5.1)

[3] Gendered and sexual fluidity are now widely accepted ideas, but in the context in which he was writing, this assertion by Foucault that sexuality was a constructed identity was a provocative one, which Spargo notes was a catalyst for the development of contemporary queer theory (17).

[4] See, for example, Kustritz 373.

[5] Played in the show by Misha Collins.

[6] This type of fan depiction is also present in the episode "The Monster at the End of This Book": When Sam and Dean find Chuck Shirley, author of the Supernatural book series, Chuck is sure they are crazed fans and asks, "Is this some kind of Misery thing?)

[7] Felschow outlines several more examples of self-deprecating writing within Supernatural (par. 6.5-6.6).

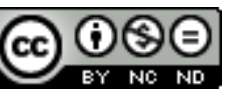

Creative Commons Attribution-NonCommercial-NoDerivatives 4.0 International License 